\title{
Epigenetic Changes in Asthma: Role of DNA CpG Methylation
}

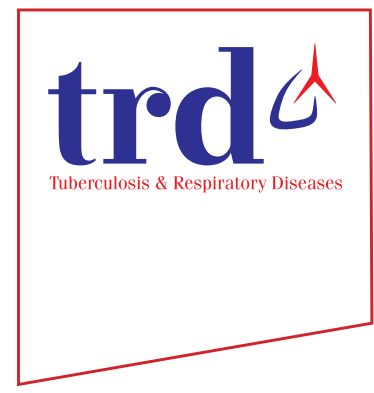

\author{
Da-Jeong Bae, Ph.D. ${ }^{1}{ }^{\circledR}$, Ji Ae Jun, M.S. ${ }^{1}$, Hun Soo Chang, Ph.D. ${ }^{2}$, Jong Sook Park, M.D., Ph.D. ${ }^{3}$ and \\ Choon-Sik Park, M.D., Ph.D. ${ }^{3}$ (iD \\ ${ }^{1}$ Department of Interdisciplinary Program in Biomedical Science Major, Soonchunhyang Graduate School, Bucheon, \\ ${ }^{2}$ Department of Environmental Health Sciences, Soonchunhyang University, Asan, ${ }^{3}$ Division of Allergy and Respiratory \\ Medicine, Genome Research Center, Soonchunhyang University Bucheon Hospital, Bucheon, Korea
}

For the past three decades, more than a thousand of genetic studies have been performed to find out the genetic variants responsible for the risk of asthma. Until now, all of the discovered single nucleotide polymorphisms have explained genetic effects less than initially expected. Thus, clarification of environmental factors has been brought up to overcome the 'missing' heritability. The most exciting solution is epigenesis because it intervenes at the junction between the genome and the environment. Epigenesis is an alteration of genetic expression without changes of DNA sequence caused by environmental factors such as nutrients, allergens, cigarette smoke, air pollutants, use of drugs and infectious agents during pre- and post-natal periods and even in adulthood. Three major forms of epigenesis are composed of DNA methylation, histone modifications, and specific microRNA. Recently, several studies have been published on epigenesis in asthma and allergy as a powerful tool for research of genetic heritability in asthma albeit epigenetic changes are at the starting point to obtain the data on specific phenotypes of asthma. In this presentation, we mainly review the potential role of DNA CpG methylation in the risk of asthma and its sub-phenotypes including nonsteroidal anti-inflammatory exacerbated respiratory diseases.

Keywords: Asthma; Gene; Environment; Aspirin; Epigenesis

\section{Introduction}

Clustering of asthmatics in families indicates that a genetic component is certainly operating. In a twin study with 7,000 same-sex born between the late 18th and the early 19th, the

Address for correspondence: Choon-Sik Park, M.D., Ph.D.

Division of Allergy and Respiratory Medicine, Genome Research Center, Soonchunhyang University Bucheon Hospital, 170 Jomaru-ro,

Wonmi-gu, Bucheon 14584, Korea

Phone: 82-32-621-5105, Fax: 82-32-621-5023

E-mail: mdcspark@daum.net

Received: Dec. 26, 2018

Revised: Apr. 19, 2019

Accepted: Aug. 30, 2019

Published online: Nov. 7, 2019

(c) It is identical to the Creative Commons Attribution Non-Commercial License (http://creativecommons.org/licenses/by-nc/4.0/). The Korean Academy of Tuberculosis and Respiratory Diseases. concordance rate for self-reported asthma in a monozygotic twin was 4 times higher than that in dizygotic twins (19\% vs. $4.5 \%)^{1}$. The heritability of asthma has been estimated up to $60 \%$ and thought to be determined by genetic factors such as nucleotide variants. Thus, the identification of single nucleotide polymorphisms (SNPs) associated with asthma and its traits has been tried for the past three decades. As the result, more than 100 loci have been found to be linked to asthma. Recently, genome-wide SNP association studies (GWASs) have confirmed that the SNPs on the genes involving antigen presentation (HLA-DR/DQ), inflammation (ORMDL3-GSD$M B$ ), and TH1/TH2 processes (IL33, IL1RL1-IL18R1, RAD50IL13, and TSLP-WDR36) are strongly associated with asthma and its subphenotypes. However, odd ratios (ORs) of these SNPs range from 0.5 to $2.0^{2}$. Attributable fractions of these SNPs to the risk of asthma were 0.269 for early-onset asthma and 0.057 for late-onset asthma. This indicates that the SNPs discovered even by the GWASs explain limited genetic effects on the risk of asthma, especially in adult asthmatics, and that their contribution to the development of asthma is smaller than expected, which was named as "missing heritability." 


\section{Considerations of Environmental Factors to Solve the Missing Heritability before the Introduction of Epigenetics}

One of the causative factors related to the missing heritability was regarded as inconsideration of environmental contributors in the well-defined specific phenotypes ${ }^{3}$. Thus, investigation of gene-environment (GxE) interactions has been studied in candidate genes and candidate environmental exposures: The well-known and extensively studied candidate interactions are the interactions between the $C D 14$ gene and environmental exposure to endotoxin (an essential component of the gram-negative bacteria walls). The T-allele (CD14/-159, rs2569190C $>T$ ) having a higher density of the membranous CD14 receptor in circulating mononuclear cells is a risk factor for allergen sensitization at high levels endotoxin exposure whereas the C-allele having a lower density of the membranous CD14 receptor is the risk factor at low levels of exposure ${ }^{4}$. Another example is that SNPs on GSDML, ORM$D L 3, I K Z F 3$, and ZPBP2 of chromosome $17 \mathrm{q} 21$ are associated with early-onset of asthma under the influence of exposure to tobacco smoke ${ }^{5}$.

The impact of the genetic variants on asthma may be enhanced in occupational diseases: A GWAS study demonstrated that SNPs of CTNNA3 (catenin alpha 3, alpha-T catenin) were significantly associated with the TDI-induced bronchospasm (OR, 5.84 for $r s 10762058)^{6}$. A drug-induced reaction such as nonsteroidal anti-inflammatory exacerbated respiratory disease (NERD) is also a good example of GxE interaction. In the cysteinyl leukotriene pathway, LTC4S, ALOX5, CysLTR1, and CysLTR2 have NERD-associated SNPs, of which OR range from 1.88 up to $9.78^{7}$. SNPs on HLA-DP1 discovered by GWAS also showed good $\mathrm{OR}^{8}$. However, SNPs discovered so far even under the consideration of environmental factors have shown small genetic effects on asthma and subphenotypes. Furthermore, the combined available data of GWAS and exonic SNPs indicate that the risk of asthma and its sub-phenotypes are mainly associated with the non-coding variants, which locate on "junk DNA of old concept."
Human genome is composed of 3,000 million base pairs of DNA $(3,000 \mathrm{Mb})$ including both protein-noncoding DNA in which contains about 20,000 functioning genes constituting only $1.5 \%$ of the total genome ${ }^{9}$. Recently, the international Encyclopedia of DNA Elements project discovered that the noncoding DNA has functional roles in regulating and promoting gene expression and is involved in the epigenetic activity and complex networks of genetic interactions ${ }^{10}$. Very recently, a multi-ancestry association study of Trans-National Asthma Genetic Consortium including 142,000 asthmatic and nonasthmatic subjects demonstrated 878 SNPs having genomewide significance at $18 \mathrm{loci}^{11}$, which are preferentially located near epigenetic markers characterizing gene enhancers in immune cells. Thus, the investigation of epigenetic marks in immune cells and airway epithelial cells has provided additional insight into the hereditary of asthma.

\section{Definition and Mechanisms of Epigenetics}

The prevalence of asthma worldwide has been increased for the past three decades, during which changes in genetic variants rarely occurred. Thus, exposal to changing exposomes (a large set of several environmental exposures: Diet, toxins, hormones impact and so on) has induced several different phenotypes of asthma ${ }^{12}$. In 1958, Nanney borrowed the term describing the inherited phenomena that could not be explained by conventional genetics, and then epigenetics was concisely defined in 2007 with the following three criteria: (1) a change in the activity of a gene that does not involve a mutation, (2) initiated by environment signals, and (3) mitotically or meiotically inherited in the absence of the change in nucleotide sequence of genomic DNA ${ }^{13}$. The mechanisms of epigenetics include (1) DNA CpG methylation, (2) histone deformation, and (3) non-coding RNA. In this review, DNA CpG methylation is mainly discussed.

The DNA methylation is the covalent addition of a methyl group to a cytosine residue in a $\mathrm{CpG}$ dinucleotide: cytosine of DNA methylation is converted to $5^{\prime}$ methylcytosine via a

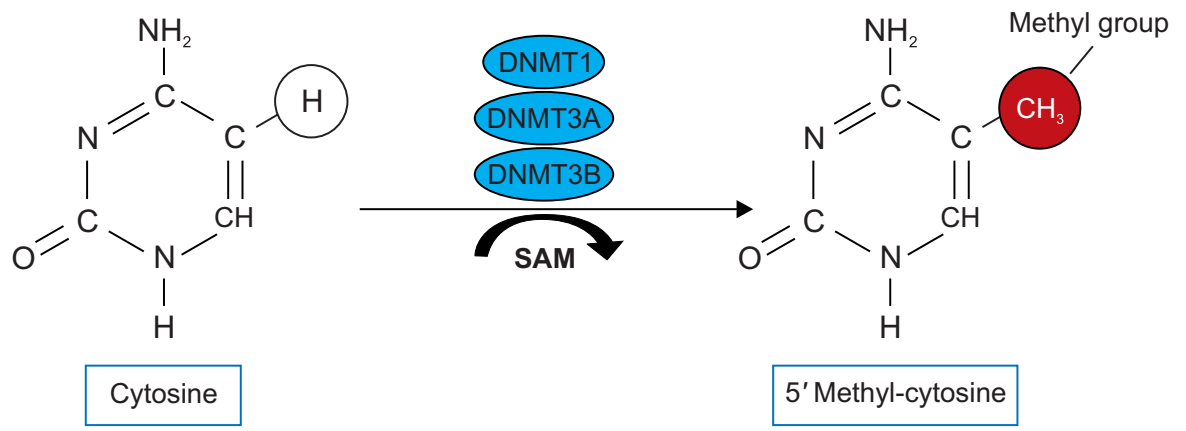

Figure 1. The DNA methylation is the covalent addition of a methyl group to a cytosine residue in a $\mathrm{CpG}$ dinucleotide. DNMT: DNA methyltransferase; SAM: S adenosyl methionine. 
covalent bond of a methyl group (Figure 1). DNA methylation is carried out in CpG occupying 1\% of DNA bases in human somatic cells. Thus the total number of $\mathrm{CpG}$ sites in humans is approximately 28 million $^{14}$, and $70 \%$ to $80 \%$ of the human DNA CpG bases are methylated. CpG islands are typically $300-3,000$ base pairs in length and are in or near approximately $40 \%$ of promoters of mammalian genes. In biochemistry, the DNA methyltransferase family of enzymes catalyze the transfer of a methyl group to DNA. De novo methyltransferases (DNMT3A and DNMT3B) newly methylate cytosines and express mainly in early embryo development. Maintenance methyltransferases (DNMT1) add methylation to DNA when one strand of DNA is already methylated (Figure 2). Methylation of $\mathrm{CpG}$ islands induces a series of changes up to histone deformation. As methylation increases in $\mathrm{CpG}$ islands by DNMT3, binding of methyl CpG binding proteins (MBP) increases at this site. MBP induces histone deacetylation by inducing histone deacetylase (HDAC) in the nucleus, increases histone methylation and chromatin becomes heterochromatin state, and finally gene expression is suppressed.

A large body of research has implicated specific time periods when individuals seem to be more susceptible to the effects of environmental exposures and other asthma triggers. These include prenatal development, early childhood, and adolescence. During these time periods, epigenetic modifications may be more likely to develop. In adult-onset asthma, it has been uncertain when epigenetic modifications develop during a lifetime. An additional question has been whether adulthood, a period when asthma often remits, may also be a period when critical epigenetic changes can be deprogrammed.

Besides the skin, the lung is the only organ that is in direct contact with the external environment. Thus, epigenetic changes occur in buccal mucosa, nasal epithelium, and bronchial epithelium as the first step in the body. Although bronchial epithelium is the best site to reflect the epigenetic changes of asthma to inhaled environmental factors, nasal and buccal cells have been frequently used for studies of the epigenetic changes as easily measurable surrogates for respiratory tract epithelium, especially in children.

\section{CpG Methylation of the Airway Epithelium}

Human skin and lung are generally considered to have the large surface area exposed to the external environment. Estimates of the surface areas that depend on height, weight, and other assumptions have led to widely accepted surface area values of $2 \mathrm{~m}^{2}$ for the skin, and $50 \mathrm{~m}^{2}$ for the lung ${ }^{15}$. Thus, lung epithelial cells are mostly affected by methylation ${ }^{16,17}$. Environmental stimuli affecting airway epithelium are categorized into outdoor and indoor factors. Outdoor stimuli that trigger or exacerbate asthma include pollens, molds, microbial and viral pathogens, environmental tobacco smoke (ETS), and ambient air pollution (AAP) such as ozone and particulate matters $(\mathrm{PM})^{12}$. Indoor environmental factors include allergens derived from dust mites, cockroaches and pets, volatile organic compounds and fine PMs especially smaller than 2.5 $\mu \mathrm{M}\left(\mathrm{PM}_{2.5}\right)$. Two methods have been applied to the study of DNA CpG methylation like SNP studies: Candidate gene approaches and epigenome-wide association study (EWAS). DNA methylation using a bisulfite sequencing of candidate genes demonstrated that exhaled NO concentration is well associated with hypomethylation of arginase-nitric oxide synthase (ARG1 and 2) in buccal cells ${ }^{18}$ and hypomethylation of interleukin 6 (ILG) and inducible nitric oxide synthase in nasal epithelia (Table 1$)^{19}$. Methylation status is diverse depending on kinds of target cells tested in the same tissue. Hypermethylated CpGs are on the promoter region $(-550$ to +87$)$ of ADAM33-expressing bronchial epithelial cells, while hypomethylated ones $(-362$ to +80$)$ are on ADAM33-expressing fibroblasts of asthmatics ${ }^{20}$. Hypermethylation on ADAM33 in bronchial epithelial cells is strongly associated with BHR, irrespective of asthma status ${ }^{20}$. This is in contrast to ADAM33

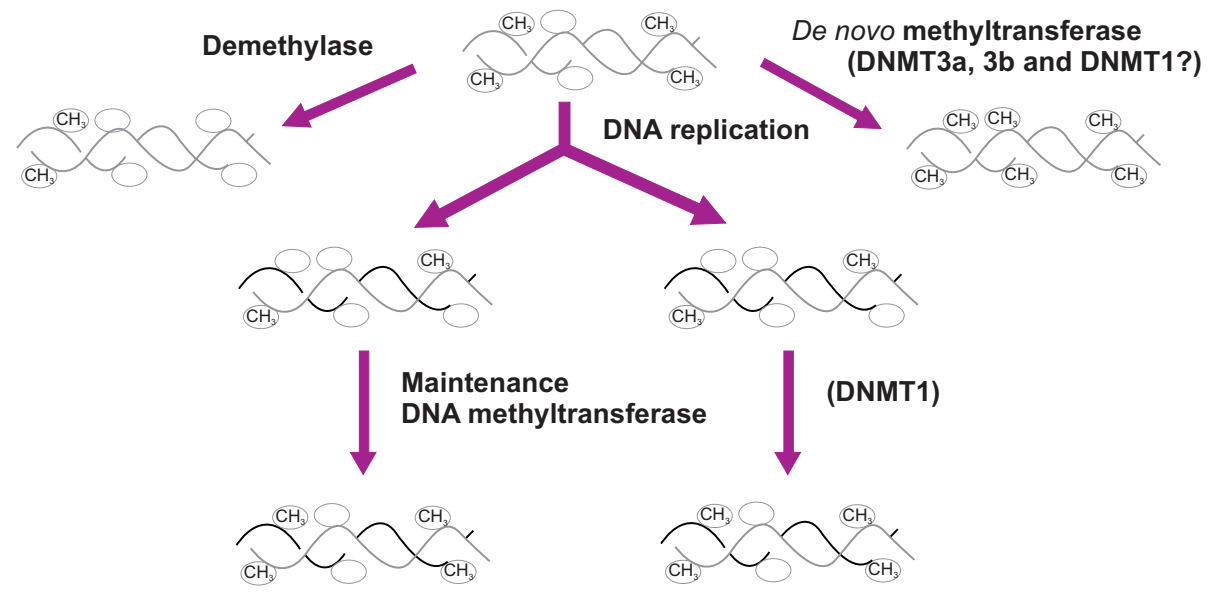

Figure 2. The DNA methyltransferase family of enzymes catalyze the transfer of a methyl group to DNA. De novo methyltransferases (DNMT3A and $D N$ $M T 3 B$ ) newly methylate cytosines and express mainly in early embryo development. Maintenance methyltransferases (DNMT1) add methylation to DNA when one strand of DNA is already methylated. 
Table 1. List of asthma-associated DNA methylations on candidate genes

\begin{tabular}{|llllll|}
\hline \multicolumn{1}{|c}{ Cell source } & Phenotype & \multicolumn{1}{c|}{ Subject } & \multicolumn{1}{c|}{ Gene } & \multicolumn{1}{c|}{ Status } & Reference \\
\hline Buccal cells & Exhaled NO & Childhood asthma & ARG1, ARG2 & Hypermethylation & Breton et al. $^{18}$ \\
Nasal epithelium & Exhaled NO & Childhood asthma & $I L 6$, iNOS & Hypomethylation & Breton et al. $^{18}$ \\
Bronchial fibroblasts & Remodeling & Asthma & ADAM33 & Hypomethylated & Baccarelli et al. $^{19}$ \\
Bronchial epithelium & BHR & Asthma & ADAM33 & Hypermethylation & Baccarelli et al. ${ }^{19}$ \\
\hline
\end{tabular}

NO: nitric oxide; $A R G 1$ and 2: arginase-nitric oxide synthase 1 and 2; IL6: interleukin 6; iNOS: inducible nitric oxide synthase; $A D A M 33$ : ADAM metallopeptidase domain 33; BHR: bronchial hyperreactivity.

Table 2. List of asthma-associated DNA methylations on EWAS

\begin{tabular}{|c|c|c|c|c|c|c|}
\hline Cell source & Size of contents & Phenotype & Subject & Gene & Status & Reference \\
\hline $\begin{array}{l}\text { Bronchial } \\
\text { epithelium }\end{array}$ & $\begin{array}{l}\text { 1,505 CpGs } \\
\text { (807 genes) }\end{array}$ & Asthma & Childhood asthma & KRT5, CRIP1 & Hypomethylation & $\begin{array}{l}\text { Stefanowicz } \\
\text { et al. } .^{22}\end{array}$ \\
\hline $\begin{array}{l}\text { Bronchial } \\
\text { epithelium }\end{array}$ & $\begin{array}{l}\text { 1,505 CpGs } \\
\text { (807 genes) }\end{array}$ & Asthma & Childhood asthma & STAT5A & Hypermethylation & $\begin{array}{l}\text { Stefanowicz } \\
\text { et al. } .^{22}\end{array}$ \\
\hline Bronchial mucosa & $\begin{array}{l}27,578 \text { CpGs } \\
\quad(15,000 \text { genes })\end{array}$ & Atopy & Adult asthma & 49 Loci in 48 genes* & Hypomethylation & Kim et al. ${ }^{23}$ \\
\hline Bronchial mucosa & $\begin{array}{l}27,578 \text { CpGs } \\
\quad(15,000 \text { genes })\end{array}$ & Atopy & Adult asthma & 6 Loci in 6 genes* & Hypermethylation & Kim et al. ${ }^{23}$ \\
\hline Buccal cells & $\begin{array}{l}\text { 1,505 CpGs } \\
\text { (807 genes) }\end{array}$ & Smoking effect $^{\dagger}$ & Children & AluYb8 and LINE1 & Hypomethylation & Breton et al. ${ }^{24}$ \\
\hline
\end{tabular}

*Names of the genes and listed in Figure 3 . ${ }^{\dagger}$ Prenatal cigarette smoke exposure.

EWAS: epigenome-wide association study; KRT5: keratin 5; CRIP1: cysteine rich protein 1; STAT5A: signal transducer and activator of transcription 5A; AluYb8: a short interspersed nucleotide element; LINE1: long interspersed nucleotide element.

hypomethylation in fibroblasts, which is speculated to be involved in airway remodeling ${ }^{21}$. A candidate $\mathrm{CpG}$ methylation approach $^{22}$, used buccal mucosa of child asthmatics on 1,505 CpG loci across 807 genes and identified a small number of DNA methylation signatures (8 sites in atopics and 6 CpGs unique to asthmatics); hypomethylation of cytokeratin 5 (KRT5), and hypermethylation of signal transducer and activator of transcription 5A (STAT5A) and cysteine-rich protein 1 (CRIP1). STAT5A transcription factor (TF) is activated by various pro-Th2 cytokines such as IL2, IL7, or TSLP. CRIP1 plays a role in cell motility, adhesion, and structure through interaction with the cytoskeletal protein actin. The promoters of STAT5A and CRIPI are hypermethylated in the epithelium of asthmatic children, resulting in decreased expression of STAT5A.

Recently, EWAS has been launched to search for changes of global CpG methylations and results of early studies are listed in Table $2^{22-24}$.

Using a chip containing 27,578 CpG loci covering more than 14,000 human RefSeq genes ${ }^{23}$, we have demonstrated a differential methylation of CpG sites in bronchial mucosa in Dermatophagoides species-specific IgE positive atopic compared to those of non-atopic asthmatics (hypermethylated 6 loci in 6 genes and hypomethylated 49 loci in 48 genes) (Figure 3A). Of the 54 differentially methylated genes (DMG) (Figure 3B), interleukin 36 receptor antagonist (IL36RN, IL1F5) and nuclear receptor subfamily 1 , group $\mathrm{H}$, member 4 (NRIH4) are related with interferon $\gamma$ (IFN- $\gamma$ ) pathway which is involved in IgE regulation and anti-viral activity. IL-36 indirectly induces IFN- $\gamma$ secretion by $\mathrm{T}$ cell, and Th1 polarization ${ }^{25}$. NRIH4 known as bile acid receptor $(B A R)$ is expressed at high levels in the liver and intestine. Chenodeoxycholic acid and other bile acids are natural ligands for BAR, which is translocated to the cell nucleus to bind to hormone response elements on DNA. Interestingly, BAR regulates the expression and activity of epithelial transport proteins involved in fluid homeostasis, such as cystic fibrosis transmembrane conduction regulator $(C F T R)^{26}$. It is unknown why this gene dominantly expressed by the cholangial ducts is methylated in bronchial epithelium. Since they are hypomethylated in atopy compared to nonatopy, they may be elevated in gene expression, and negatively regulate IFN- $\gamma$ pathway leading to suppression of atopic manifestation.

In addition to these genes, the atopics had hypomethylated caspase 1, which activates IL18, an IL-1-like cytokine to increase IgE production in $\mathrm{CD} 4^{+} \mathrm{T}$ cells. IL-18 and T-cell receptor-mediated stimulation could induce naïve $\mathrm{CD} 4^{+} \mathrm{T}$ cells to develop into IL-4-producing cells in vitro. ILIR1 is a receptor for $I L I A, I L I B$, and $I L I R N$ which mediates interleukin-1-dependent activation of nuclear factor $\kappa \mathrm{B}$ and mitogen-activated 

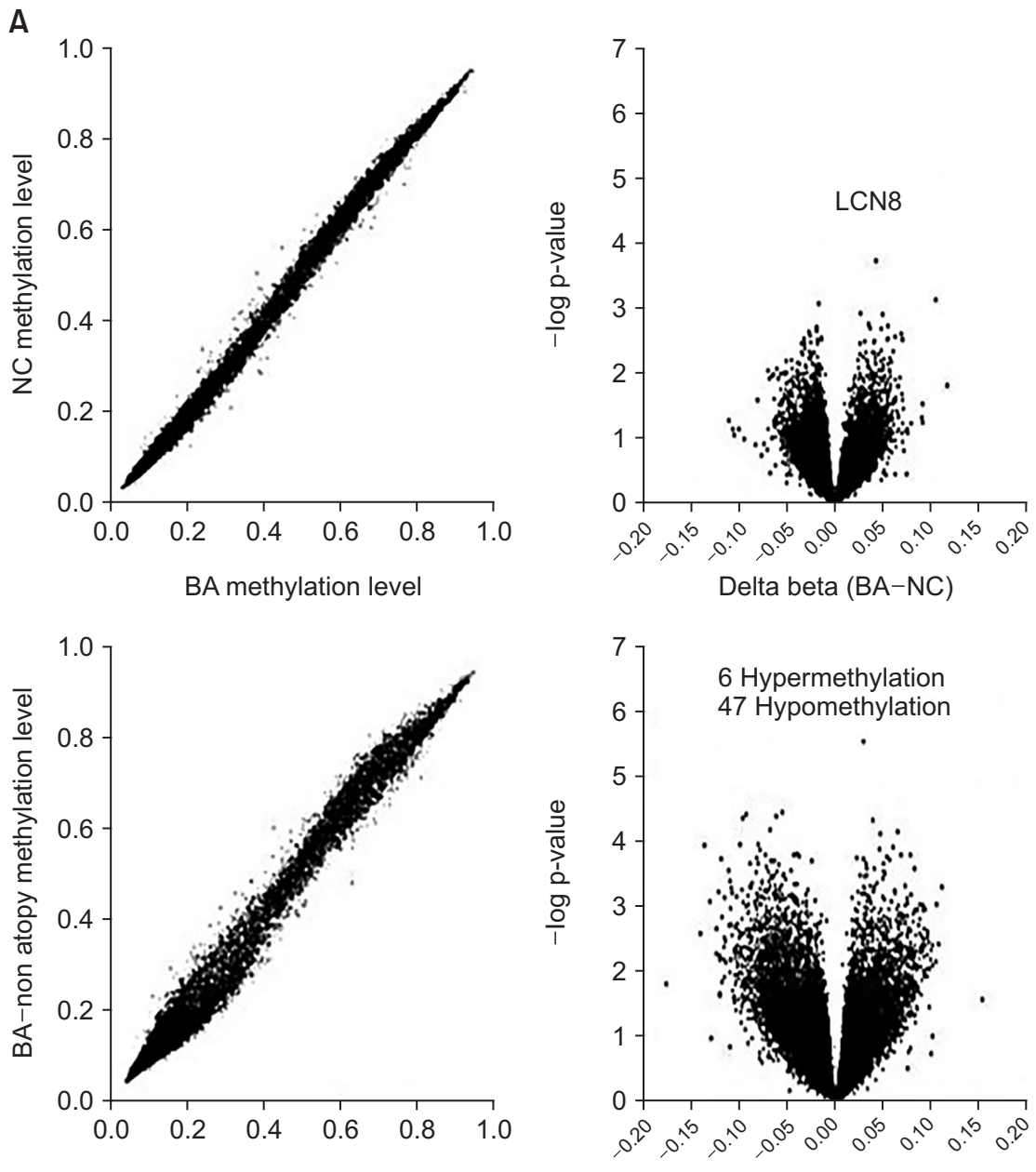

BA-atopy methylation level

Delta beta (BA atopy-non atopy)
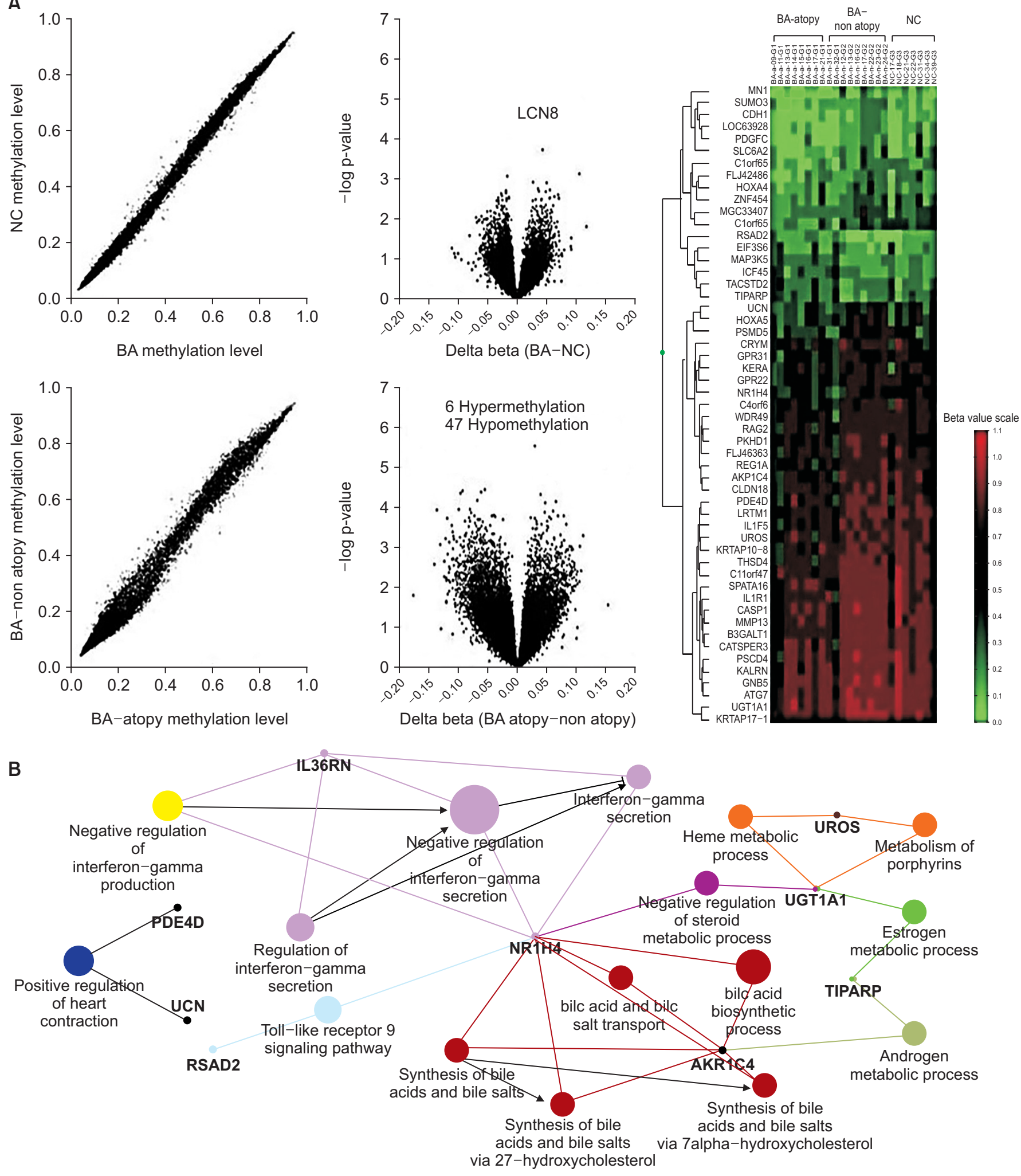

Figure 3. Differential methylation of CpG sites in bronchial mucosa between Dermatophilosis's species-specific IgE positive atopic and nonatopic asthmatics (A), a network analysis of 54 differentially methylated genes (B). BA: bronchial asthma; NC: normal control. 
protein kinase which are main mediators. Furthermore, $I L 1 \beta$ mediates co-stimulation of IFN- $\gamma$ production from Thl cells ${ }^{27}$. Thus, hypomethylated $C A S P I$ and $I L I R I$ are expected to elevate their gene levels with alteration of Thl regulation. In addition, radical SAM domain-containing 2 (RSAD2), also known as virus inhibitory protein (Viperin) is hypermethylated in atopic compared to non-atopic asthma. This protein plays a major role in the antiviral state induced by type I and type II interferon function via the regulation of the Toll-like receptor (TLR) 7 and TLR9-IRAK1 signaling axis in plasma dendritic cells. Thus, the decrease of $R S A D 2$ gene may be a relation of respiratory viral infection-susceptibility in atopics.

\section{CpG Methylation of the Immune Cells}

Despite of the limitation that cells are present in different proportions among cases and control subjects, many methylation studies have relied on DNA isolated from unfractionated peripheralblood leukocytes (PBL) due to easy access and availability. Moreover, methods have been recently developed to infer the proportion of immune cell populations in PBL from the DNA methylation data. In addition, asthma has major immunologic components of pathogenesis and epigenetic mechanisms specifically affect the expression of TFs involved in the development of Th1, Th2, Th17, and regulatory T cell (Treg) cells. Thus, DNA methylation profiles of PBL have been very useful to identify the epigenetic change of immune status. Results of early studies CpG methylation changes of immune cells are summarized in Table $3^{28-35}$.

Asthmatics, especially atopics, have hypomethylation of IL-4 promoter and hypermethylation of IFN- $\gamma$ promoter of $\mathrm{T}$ cells. In vitro differentiation of $\mathrm{CD}^{+} \mathrm{T}$ cells down the Th1 pathway is accompanied by progressive demethylation of
CpG sites in the IFN- $\gamma$ promoter, which is mostly marked in the neonate ${ }^{28}$. House dust mites increase unmethylation of CpG in the IL-4 gene on $\mathrm{CD}^{+} \mathrm{T}$ cells with concomitantly increased gene levels ${ }^{36}$. AAP also initiate the transformation of Th1 to Th2 cells ${ }^{37}$, leading to increase of the pro-atopic cascade of Th2 cytokines (IL-4 and IL-13) in the bronchoalveolar lavage, sputum, and blood of patients with asthma. Regulatory $\mathrm{T}$ cell numbers are reduced in the lung and peripheral blood of subjects with asthma. Forkhead box transcription factor 3 (Foxp3) is important in Treg-cell development and function. Increased exposure to AAP leads to hypermethylation of the Foxp3 locus ${ }^{38}$.

Recently, EWAS has revealed new differentially methylated CpG (DMC): Asthmatics living in the inner city had 55 DMCs, some of which are involved in T-lymphocyte biologies such as runt-related transcription factor $3(R U N X 3)$ as well as IL4 and IL13. RUNX3 is a TF to regulate CD4/CD8 T-lymphocyte development by interacting with T-box and silencing IL-4 expression. In addition, other genes involved in the maturation and function of T lymphocytes (TIGIT) and nautral killer cells (KIR2DL4, KIR2DL3, KIR3DL1, and KLRD1) are also differently methylated. Highly striking DMCs are located on biologically noble genes: alkaline phosphatase, tissuenonspecific isozyme ( $A L P L)$, which modulates host-bacterial interactions by dephosphorylating lipopolysaccharide and Kruppel-like factor 6 (KLF6), which activates iNO2 synthase 1 and transforming growth factor $\beta$ during influenza $A$ virus and respiratory syncytial virus infection. Also, $A L P L$ discriminates eosinophilic asthma from other inflammatory phenotypes $^{39}$. Additional DMCs in the promoter have been found on candidate genes including arachidonate 12-lipoxygenase (ALOX12), CCL5, IL2RA, TBX21, and FCER2 $2^{40}$. Taken together, these data indicate that many of asthma-related genes may be differentially expressed by changes of $\mathrm{CpG}$ methylation as

Table 3. List of asthma-associated DNA methylations of peripheral, umbilical cord blood, and bronchoalveolar lavage cells

\begin{tabular}{|c|c|c|c|c|c|}
\hline Cell source & Environment & Subject & Gene & Status & Reference \\
\hline CD4(+) T cells & HDM & Children and adults & $I F N-\gamma$ & Hypermethylation & White et al. ${ }^{28}$ \\
\hline CD4(+) T cells & HDM & Adult asthmatics & IL4 & Hypermethylation & Shang et al. ${ }^{29}$ \\
\hline Peripheral Treg cells & PAH & Childhood asthma & Foxp3 & Hypermethylation & Lluis et al. ${ }^{30}$ \\
\hline Umbilical cord blood & PAH & Childhood asthma & ACSL3 59 & Hypermethylation & Perera et al. ${ }^{31}$ \\
\hline Whole blood DNA & Smoke & Childhood asthma & FRMD4A, Cllorf52 & Hypermethylation & Breton et al. $^{32}$ \\
\hline \multirow[t]{2}{*}{ PBMC } & PAH, ETS & Childhood asthma & $\begin{array}{l}\text { IL4, IL3, RUNX3, TIGIT, } \\
\text { KIR2DL4, KIR2DL3, KIR2DL1, } \\
\text { KLRD1, ALPL }\end{array}$ & Hypermethylation & Yang et al. ${ }^{33}$ \\
\hline & & & & Hypermethylation & Yang et al. ${ }^{34}$ \\
\hline PBMC & AAP & Childhood asthma & FCER2, TGFB1 & Hypermethylation & Rastogi et al. $^{35}$ \\
\hline
\end{tabular}

HDM: house dust mites; IFN- $\gamma$ : interferon $\gamma$; IL4: interleukin 4; Treg: regulatory T cell; PAH: polyaromatic hydrocarbon; ACSL3: acyl-CoA synthetase long chain family member 3; FRMD4A: FERM domain containing 4A; PBMC: peripheral blood mononuclear cell; ETS: environmental tobacco smoke; RUNX3: runt-related transcription factor 3; TIGIT: T-cell immunoreceptor with Ig and ITIM domains; KIR: killer cell immunoglobulin-like receptor; AAP: ambient air pollution. 
well as genetic variants.

\section{Smoke and Air Pollutants-Related CpG Methylation and Its Mechanism}

Among the atmospheric environmental factors, smoking is the most important risk factor of asthma. Birth cohort studies have demonstrated childhood asthma incidence to be higher in mothers who smoked during pregnancy ${ }^{41}$. Cigarette smoke modulates gene expression through DNA damage and subsequent recruitment of DNMTs via several mechanisms: carcinogens in cigarette smoke such as polycyclic aromatic hydrocarbon (PAH) can cause double-stranded breaks damage of DNA following recruitment of DNMT1 to modulate methylation state ${ }^{42}$. In fact, prenatal tobacco smoke is associated with lower DNA methylation for AluYb8 (short interspersed nucleotide element) repetitive elements and long interspersed nucleotide element (LINEI) in buccal cells in children, especially in those with the common GSTM1 null genotype $^{24}$, suggesting a novel interaction between DNA CpG methylation and genotypic variants.

EWAS demonstrated that cigarette smoke results in global hypomethylation: maternal smoking is associated with the placenta with some DMCs, which exhibit altered gene expression patterns ${ }^{43}$. In a study using whole blood DNA samples of age 5-12 with an available history of intrauterine exposure to smoke, 19 CpG loci of 27,578 loci were significantly associated with prenatal smoke. Among them, smoke exposure was associated with the $2 \%$ increase in mean CpG methylation in FRMD4A and Cllorf52 compared to no exposure (Table 3). The epigenetic modification of the FRMD4A plays a role in conferring an increased risk of nicotine dependence in the offspring of mothers who smoke during pregnancy ${ }^{44}$.

AAP also has a profound epigenetic effect on not only immune cells but also airway epithelium even in the fetal period. In a longitudinal cohort of 700 children in New York City, the prevalence of asthma (25\%) is among the highest in the United States. This high risk may in part be caused by transplacental exposure to traffic-related $\mathrm{PAHs}^{31}$. Fetal tissues demonstrated epigenetic markers: methylation of the longchain-fatty-acid-CoA ligase 3 (ACSL3) in cases of maternal airborne PAH exposure exceeding $2.41 \mathrm{ng} / \mathrm{m}^{3}$ and asthma symptoms in children before age 5 . Thus, methylated ACSL3 in umbilical cord cells may be a surrogate endpoint for transplacental PAH exposure and/or a potential biomarker for environmentally-related childhood asthma. In addition to ETS, low maternal intake of foods containing vitamin $\mathrm{E}$ and zinc or use of antibiotics during pregnancy may increase the risk for childhood asthma ${ }^{45}$, however, in-depth discussion is omitted here because they did not directly contact with the airways.

\section{Relation of CpG Methylation with SNPs and Transcriptome}

Very recently, an EWAS was published as the first study to combine with an extensive validation and replication study of CpG sites in more than 5,000 children ${ }^{46}$. This large consortium-based meta-analysis identified 14 DMC sites in whole blood in childhood asthma and the DMC continued until adolescence. There asthma-associated CpG sites were annotated to eosinophils and $\mathrm{CD}^{+} \mathrm{T}$ cells and natural killer cells. Thus, asthma-associated DNA methylation patterns identified in this study are likely to be the result of postnatal environmental influences, pathophysiological processes related to asthma, or both. Importantly, strongly reduced methylation of the $\mathrm{CpG}$ sites in purified eosinophils retained an association with asthma, highlighting that eosinophils are epigenetically altered in asthma. Furthermore, CpG site-related SNPs (cgSNPs) and relation with transcriptome were evaluated with the differentially CpG methylation using in silico analysis. Some SNPs influence the existence of $\mathrm{CpG}$ sites, where DNA modification such as methylation occurs. These SNPs can lead to gain or loss of CpG sites and are defined as cgSNPs. Mutations involving loss of CpG sites were associated with reduced levels of methylation in about $20 \%$ of $\mathrm{CpG}$ sites using The Cancer Genome Atlas (TCGA) data ${ }^{47}$. Thus, SNPs regulating blood eosinophil counts significantly overlap with DMCs on the genes, such as IL5, IL33, ILIRLI, and TSLP $P^{48}$.

\section{Environmental Factor-Induced Temporal Changes of CpG Methylation}

Despite the potential clinical relevance, the interpretation of cross-sectional epigenetic studies on asthma is problematic because it is impossible to determine whether the alteration of methylation is a cause or a consequence. Accordingly, the trajectory analysis of prenatal and early postnatal period or those of changes after the experimental challenge of environmental factors are good models to solve time- and environmentdependent epigenetic changes. Very recently, a study using buccal cells from 10-year-old monozygotic twin children identified asthma-associated DMCs, which were mapped to genes that cluster in immunoregulatory and proinflammatory pathways (Table 4$)^{49-54}$. Among the top-ranked genes, heparan-alpha-glucosaminide N-acetyltransferase (HGSNAT) was consistently hypermethylated in asthma-affected twins compared to their unaffected co-twins. Interestingly, HGSNAT gene expression in the lysosomal pathway is down-regulated in pediatric allergic asthma cases compared to controls. Also, persistently discordant for asthma at age 18 is associated with the hypomethylated homeobox protein HB24 (HLX), which has been previously implicated in childhood asthma as a regulator of $\mathrm{Th}_{1}$ differentiation and a suppressor of $\mathrm{TH}_{2} \mathrm{com}$ - 
Table 4. List of methylation using trajectory analysis and experimental exposure to environmental factors

\begin{tabular}{|c|c|c|c|c|c|c|}
\hline Cell source & Environment & Phenotype & Subject & DMC & Methylated gene* & Reference \\
\hline Buccal cell & $\begin{array}{l}\text { Tobacco smoke and } \\
\text { microbial and viral } \\
\text { agents }\end{array}$ & Asthma at age 10 & $37 \mathrm{MZ}$ twin pairs & Top 10 DMC & $\begin{array}{l}\text { Hypermethylated } \\
H G S N A T\end{array}$ & Murphy et al. ${ }^{49}$ \\
\hline Buccal cell & $\begin{array}{l}\text { Tobacco smoke and } \\
\text { microbial and viral } \\
\text { agents }\end{array}$ & Asthma at age 18 & $37 \mathrm{MZ}$ twin pairs & Top 10 DMC & $\begin{array}{l}\text { Hypomethylated } \\
\text { HLX }\end{array}$ & Murphy et al. ${ }^{49}$ \\
\hline $\begin{array}{l}\text { Cord blood } \\
\text { cell }\end{array}$ & $\begin{array}{l}\text { Maternal, paternal } \\
\text { asthma, smoking } \\
\text { during pregnancy }\end{array}$ & Asthma at age 9 & Infant immune study & $589 \mathrm{DMC}$ & $\begin{array}{l}\text { Hypermethylated } \\
S M A D 3\end{array}$ & DeVries et al. ${ }^{50}$ \\
\hline $\begin{array}{l}\text { Bronchial } \\
\text { epithelium }\end{array}$ & $\begin{array}{l}\text { Diesel exhaust and } \\
\text { allergen }\end{array}$ & $\begin{array}{l}\text { Acute airway } \\
\text { injury at } 48 \\
\text { hours }\end{array}$ & $\begin{array}{l}\text { Adult asthmatics } \\
\text { Adult asthmatics }\end{array}$ & $7 \mathrm{DMC}$ & $\begin{array}{l}\text { Hypomethylated } \\
T B X 3\end{array}$ & Clifford et al. ${ }^{51}$ \\
\hline $\begin{array}{l}\text { Bronchial } \\
\text { epithelium }\end{array}$ & $\begin{array}{l}\text { Diesel exhaust and } \\
\text { allergen }\end{array}$ & $\begin{array}{l}\text { Repeated injury } \\
\text { after } 4 \text { weeks }\end{array}$ & Childhood asthmatics & $500 \mathrm{DMC}$ & $\begin{array}{l}\text { Hypomethylated } \\
\text { Hox gene }\end{array}$ & Clifford et al. ${ }^{51}$ \\
\hline Buccal cell & $\mathrm{PM}_{2.5}$ and vanadium & 6 Days' exposure & Childhood asthmatics & $13 \mathrm{DMC}$ & $\begin{array}{l}\text { Hypomethylated } \\
\text { IL4 and } \\
\text { hypermethylated } \\
I F N-\gamma\end{array}$ & $\begin{array}{l}\text { Lovinsky-Desir } \\
\text { et al. }^{52}\end{array}$ \\
\hline Buccal cell & Black carbon & Exercise & Childhood asthmatics & $9 \mathrm{DMC}$ & $\begin{array}{l}\text { Hypomethylated } \\
\text { FOXP3 }\end{array}$ & Jung et al. ${ }^{53}$ \\
\hline Buccal cell & Black carbon & $\begin{array}{c}5 \text { Days after } \\
\text { exposure }\end{array}$ & Childhood asthmatics & $4 \mathrm{DMC}$ & $\begin{array}{c}\text { Hypomethylated } \\
I L 4, N O S 2 A\end{array}$ & Jung et al..$^{53}$ \\
\hline PBMC & $\mathrm{NO}_{2}, \mathrm{CO}$, and $\mathrm{PM}_{2.5}$ & 2 Years exposure & Childhood asthmatics & & $\begin{array}{c}\text { Hypomethylated } \\
\text { Foxp3, IL10 }\end{array}$ & Prunicki et al. ${ }^{54}$ \\
\hline
\end{tabular}

*Representative genes are presented: HGSNAT (heparan alpha glucosamine N-acetyltransferase), HLX (homeobox protein HB24), SMAD3 (SMAD family member 3), TBX3 (T-Box transcription factor TBX3), Hox (homeobox), IL4 (interleukin 4), IFN- (interferon $\gamma$ ), FOXP3 (forkhead box p3), NOS2A (nitric oxide synthase 2).

MZ: monozygotic; DMC: differentially-methylated CpG site; $\mathrm{PM}_{2.5}$ : particulate matters especially smaller than $2.5 \mu \mathrm{M}$; PBMC: peripheral blood mononuclear cell.

mitment. In another birth cohort trajectory study of childhood asthma, neonatal immune cells in cord blood mononuclear cells harbored 589 DMCs that distinguished children who did and did not have asthma by age $9^{50}$. Among them, SMAD3 methylation in the neonates with maternal asthma was strongly and positively associated with neonatal production of cord blood mononuclear cell-derived IL-1 $\beta$, an innate inflammatory mediator.

From a couple of years ago, longitudinal changes of epigenome have been studied on bronchial epithelium after inhalation of allergens, air pollutants or other triggering agents. Sequential insults with allergens and diesel extracts (DE) significantly accentuate changes in CpG methylation in comparison with a single exposure: in adult subjects with birch pollen allergy, while exposure to allergen alone led to changes in seven CpG sites at 48 hours, when the same lung was exposed to allergen and DE separated by approximately 4 weeks, more than 500 DMCs were observed ${ }^{51}$. These findings suggest that specific exposures can prime the lung for changes in DNA methylation induced by a subsequent insult.
Of particular note, a significant decrease in DNA methylation was found in response to allergen following prior DE exposure in eight CpGs located upstream of the promoter of the T-box transcription factor 3 (TBX3), a member of T-box family of TFs. In the other hand, a significant decrease in DNA methylation in response to DE following prior allergen exposure was present in 19 CpGs associated with homeotic (Hox) genes family ${ }^{51}$. This data indicates that the sequences of exposures to environmental factors are more critical for the gene expression induced by altered CpG methylation.

AAP has been regarded as hazardous even in short-term exposure of several days. Using six-day integrated levels of air pollutants in urban children who live in New York City (age 9-14), indoor exposure to fine $\mathrm{PM}_{2.5}$ and vanadium (V) are associated with decreased lung function and altered buccal cell DNA methylation of IL4 and IFN- $\gamma$, respectively ${ }^{55}$. A very interesting study on the epigenetic effect of exercise was performed in these children: exercise decreases DNA methylation on the promoter of $F O X P 3$, an indicator of greater Treg function in cases of higher black carbon (BC) exposure $(>1,200$ 
$\mathrm{ng} / \mathrm{m}^{3}$ ) with concomitant increase of lung function, but not in lower BC exposure ${ }^{52}$. In the same children, higher levels of $\mathrm{BC}$ were associated with lower methylation of IL4 promoter $\mathrm{CpG}^{-48}$ and NOS2A CpG ${ }^{+5099}$ with increased FeNO, and this association was more apparent especially in cockroach sensitized children ${ }^{53}$. Very recently, short- and long-term (up to 2 years) exposure to $\mathrm{NO}_{2}, \mathrm{CO}$, and $\mathrm{PM}_{2.5}$ were revealed to link to regional DNA methylation differences including Foxp3 and ILIO in peripheral blood mononuclear cell of asthmatics. Furthermore, for any given individual, these changes tend to be sustained over time up to 2 years ${ }^{54}$. Thus, these trajectory and experimental challenge studies revealed that epigenetic mechanisms are working as causative contributors to the genetic changes of asthma.

\section{Global Changes in CpG Methylation of Nasal Polyps from Subjects with NERD}

Epidemiological studies have shown that regular use of non-steroidal anti-inflammatory drugs (NSAIDs) reduces the risk of the development of at least some cancers via wellknown targets including cyclooxygenase (COX) 1 and COX2, and other intracellular pathways ${ }^{56}$. Also, NSAIDs induce promoter demethylation of secreted protein acidic and rich in cysteine gene (SPARC, Osteonectin) by repressing DNMT expression $^{57}$. In agreement with experimental data, an epidemiological study has shown that chronic aspirin use may be associated with a lower prevalence of E-cadherin $(\mathrm{CDHI})$ promoter methylation in non-neoplastic gastric mucosa ${ }^{58}$. However, there are few studies on DNA CpG methylation in
A

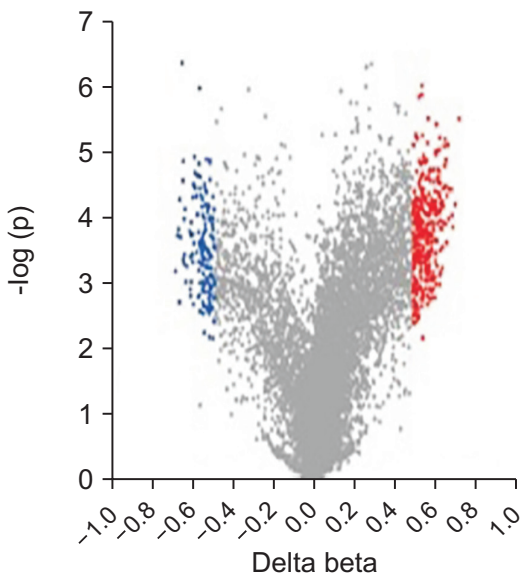

D

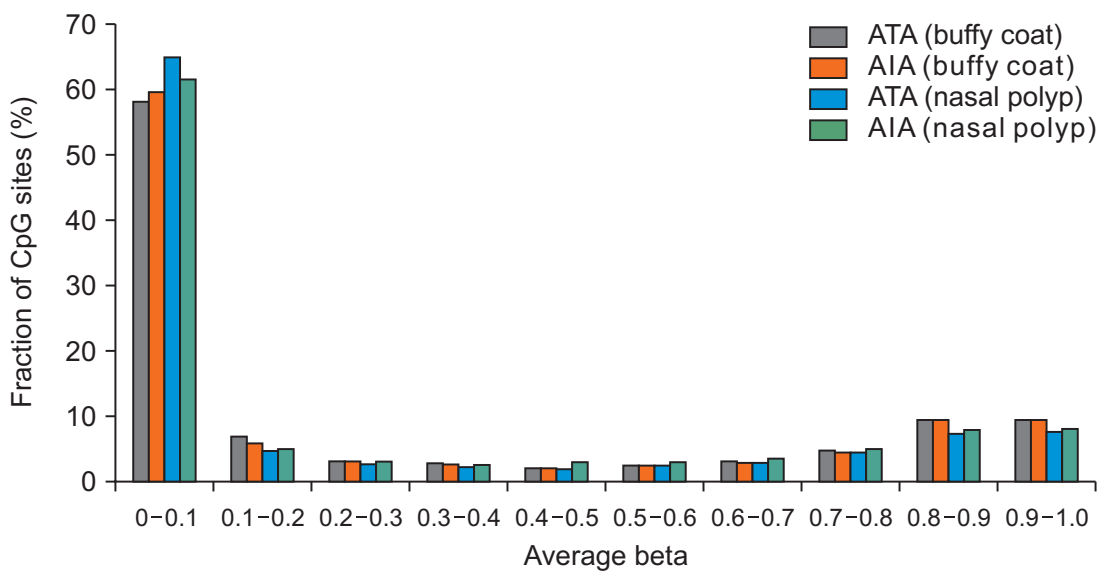

B

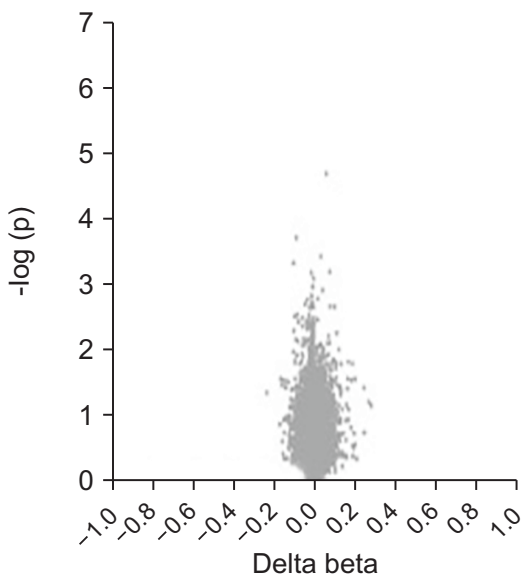

Delta beta

C

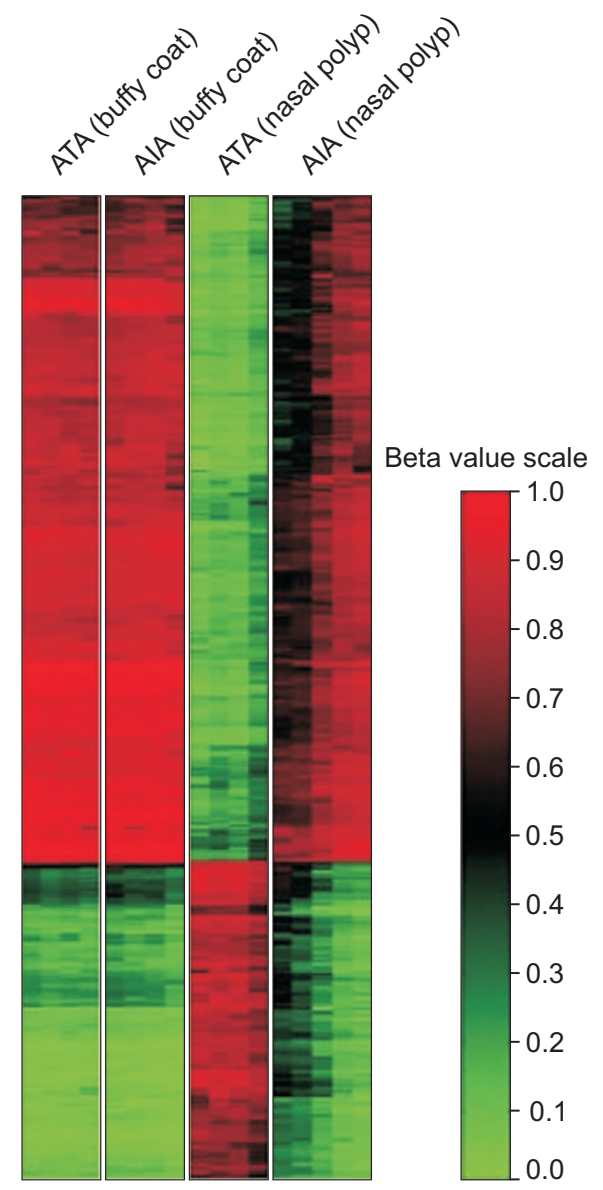

Figure 4. Summary of DNA methylation data. (A, B) Volcano plot of differential methylation level between aspirin-induced asthma (AIA) and aspirin-tolerant asthma (ATA) in nasal polyp tissues (A) and buffy coat samples (B). Red dots: delta-beta $\geq 0.5$ and $\mathrm{p} \leq 0.01$, blue dots: delta beta $\leq-0.5$ and $\mathrm{p} \leq 0.01$, grey dots: $-0.5 \leq$ Deltabeta $\leq 0.5$ and $p>0.01$. Delta-Beta: difference of DNA methylation level (subtracting the DNA methylation level of ATA from AIA). $-\log (p)$ : $\log$-transformed t-test p-values. (C) Distribution of the DNA methylation level of AIA and ATA in buffy coat and nasal polyp. Average beta: DNA methylation level (0 to 1). (D) Heatmap of 490 differentially methylated CpGs between AIA and ATA in buffy coat and nasal polyp. 
NERD. In a genome-wide CpG methylation study using nasal polyps in subjects with NERD and aspirin-tolerant asthma patients $^{59}, 332$ CpG sites on 296 genes were hypomethylated, and 158 sites on 141 genes were hypermethylated in NERD (Figure 4). Thus, NERD associated-proportion of global DMC is $1.78 \%$ ( $490 / 27,587 \mathrm{CpGs})$, which was about 10 times greater than $0.19 \%(53 / 27,578 \mathrm{CpGs})$ in atopic bronchial epithelium ${ }^{23}$. The 490 DMCs are located on 437 genes, thus the global proportion of DMG is $3.02 \%$ (437/14,457 genes). Ontology classification demonstrated 259 genes on arachidonate pathways (Table 5). Among them, 66 genes are differentially methylated (25.48\%), which is 10 times greater than that $(3.02 \%)$ of global DMG, indicating that genes in arachidonate pathways are much more labile to CpG methylation in NERD. It has been well known that genetic variants in arachidonate pathways such as LCT4s, 5LO, Cyst LR1, and Cyst LR2 exert their genetic effects on the development of $\mathrm{NERD}^{7}$. Taken together, these data indicate that the subjects with NERD may have genetically and epigenetically susceptible genes on arachidonate pathways to NSAIDs or other factors and that the interrelation between genetic and epigenetic impacts should be evaluated. Finally, these genetic variants and epigenetic markers would be developed to predict the risk of NERD in the near future.

Table 5. Number of DMG in arachidonic acid pathways in NERD compared to those in ATA

\begin{tabular}{|lccc|}
\hline \multicolumn{1}{|c}{ Ontology } & $\begin{array}{c}\text { No. of } \\
\text { genes }\end{array}$ & $\begin{array}{c}\text { DMG, } \\
\mathbf{p}<\mathbf{0 . 0 5}\end{array}$ & Percentage \\
\hline $\begin{array}{l}\text { Arachidonic acid binding } \\
\begin{array}{l}\text { Arachidonic acid } \\
\text { metabolism }\end{array}\end{array}$ & 5 & 3 & 60.0 \\
\hline $\begin{array}{l}\text { PTGS biosynthetic } \\
\text { process }\end{array}$ & 25 & 34 & 54.8 \\
$\begin{array}{l}\text { Leukotriene biosynthesis } \\
\text { process }\end{array}$ & 20 & 3 & 20.0 \\
\hline $\begin{array}{l}\text { Arachidonic acid } \\
\text { products }\end{array}$ & 93 & 13 & 14.0 \\
\hline $\begin{array}{l}\text { Leukotriene products } \\
\text { Lipoxygenase }\end{array}$ & 38 & 5 & 13.2 \\
\hline Total & 259 & 66 & 12.5 \\
\hline
\end{tabular}

Ontology classification of the 36,127 genes in the AmiGo2 (http:// amigo.geneontology.org/amigo/search/ontology) includes 259 genes in arachidonate pathways. The number of 437 DMG constitutes $1.20 \%$ of the total 36,127 genes and 66 DMG constitutes $25.5 \%$ of 259 genes in the arachidonic acid pathways.

DMG: differently methylated genes; NERD: nonsteroidal anti-inflammatory exacerbated respiratory disease; ATA: aspirin-tolerant asthma; PRGS: prostaglandin-endoperoxide synthase.

\section{Epigenetic Therapy}

Since the DNA CpG methylation changes described above are much more reversible than the DNA mutation, many treatment strategies are currently under investigation. Studies in dietary manipulation have demonstrated that methyl-rich diets are associated with hypermethylation of the epigenome. In humans, methyl donors for DNA methylation are mostly derived from dietary methyl groups nutrients (folate, vitamin B12, and choline) act as methyl donors. Methyl donors affect DNA methylation and immune responses such as Th17, Thl/ Th2 balance and Treg generation in concert with vitamins (A, $\mathrm{C}$, D, and $\mathrm{E}$ ). While these findings have generated considerable interests, their relevance to clinical efficacy is still unclear because of the high doses of methyl donors employed in the dietary intervention and insufficient evidence to recommend the use of any vitamin supplement or nutrient acting as a methyl donor for the prevention or treatment of asthma.

Dysregulation of epigenetic events leads to cardiovascular disease, neurological disorders, metabolic disorders, and cancer and asthma as well. Therefore, identifying drugs that inhibit these epigenetic changes are of great clinical interest in all clinical fields. There are major classes of epigenetic drugs currently in use, such as DNA methylation inhibiting drugs, bromodomain inhibitors, histone acetyltransferase inhibitors, HDAC inhibitors, protein methyltransferase inhibitors, and histone methylation inhibitors. In the present review, methylation inhibiting drugs are discussed. From the U.S. Food and Drug Administration, 5-azacytidine (Aza; market name Vidaza), a DNMT inhibitor, was approved in 2004 and decitabine was approved in $2006^{60}$. Recently zebularine, 5-fluoro- $2^{\prime}$ deoxycytidine was recognized and has been studied as an anticancer therapeutic agent. RG108 is a relatively new small molecule DNA methylation inhibitor that is currently being investigated. This drug does not intercalate into target DNA or bind to the DNMT1 gene, but rather binds to and directly inhibits the DNMT1 enzyme active site. However, the abovementioned drugs are currently studied for clinical application to date.

\section{Conclusion}

Epigenetic influences and mechanisms have been clarified in allergic diseases and asthma, but there are still many questions to be solved yet. The most complex situation is when both the gene and the environment are unknown. Also, the lack of exposomes is a big huddle to solve the geneepigenome-environment interaction. Thus, more information on exposomes is collected such as microbiome, metabolome, indoor living conditions, socioeconomic status, and stress. Additional measurement of miRNA and histone modification will be conducted together, and all of these data will be 
analyzed by multi-Omic approaches. If accurate influence and mechanisms of epigenetics are revealed, prevention and control strategies for asthma and its subtypes will be developed.

\section{Authors' Contributions}

Conceptualization: Park CS. Data curation: Bae DJ, Jun JA. Writing - original draft preparation: Bae DJ, Park JS, Chang HS, Park CS. Writing - review and editing: Bae DJ, Park CS. Approval of final manuscript: all authors.

\section{Conflicts of Interest}

No potential conflict of interest relevant to this article was reported.

\section{Funding}

This study was supported by a grant from the National Research Foundation of Korea (NRF) funded by the Ministry of Education (2017-R1A2B40126). DJ BAE was supported by the Basic Science Research Program of NRF (2017R1A6A3A01076548).

\section{References}

1. Edfors-Lubs ML. Allergy in 7000 twin pairs. Acta Allergol 1971;26:249-85.

2. Moffatt MF, Kabesch M, Liang L, Dixon AL, Strachan D, Heath $\mathrm{S}$, et al. Genetic variants regulating ORMDL3 expression contribute to the risk of childhood asthma. Nature 2007;448:4703.

3. Manolio TA, Collins FS, Cox NJ, Goldstein DB, Hindorff LA, Hunter DJ, et al. Finding the missing heritability of complex diseases. Nature 2009;461:747-53.

4. Vercelli D. Learning from discrepancies: CD14 polymorphisms, atopy and the endotoxin switch. Clin Exp Allergy 2003;33:153-5.

5. Bouzigon E, Corda E, Aschard H, Dizier MH, Boland A, Bousquet J, et al. Effect of 17q21 variants and smoking exposure in early-onset asthma. N Engl J Med 2008;359:1985-94.

6. Kim SH, Cho BY, Park CS, Shin ES, Cho EY, Yang EM, et al. Alpha-T-catenin (CTNNA3) gene was identified as a risk variant for toluene diisocyanate-induced asthma by genomewide association analysis. Clin Exp Allergy 2009;39:203-12.

7. Park SM, Park JS, Park HS, Park CS. Unraveling the genetic basis of aspirin hypersensitivity in asthma beyond arachidonate pathways. Allergy Asthma Immunol Res 2013;5:258-76.

8. Park BL, Kim TH, Kim JH, Bae JS, Pasaje CF, Cheong HS, et al. Genome-wide association study of aspirin-exacerbated respiratory disease in a Korean population. Hum Genet 2013;132:313-21.

9. Ezkurdia I, Juan D, Rodriguez JM, Frankish A, Diekhans M, Harrow J, et al. Multiple evidence strands suggest that there may be as few as 19,000 human protein-coding genes. Hum Mol Genet 2014;23:5866-78.

10. ENCODE Project Consortium. An integrated encyclopedia of DNA elements in the human genome. Nature 2012;489:57-74.

11. Demenais F, Margaritte-Jeannin P, Barnes KC, Cookson WOC, Altmuller J, Ang W, et al. Multiancestry association study identifies new asthma risk loci that colocalize with immunecell enhancer marks. Nat Genet 2018;50:42-53.

12. Ho SM. Environmental epigenetics of asthma: an update. J Allergy Clin Immunol 2010;126:453-65.

13. Ptashne M. On the use of the word 'epigenetic'. Curr Biol 2007;17:R233-6.

14. Stevens M, Cheng JB, Li D, Xie M, Hong C, Maire CL, et al. Estimating absolute methylation levels at single-CpG resolution from methylation enrichment and restriction enzyme sequencing methods. Genome Res 2013;23:1541-53.

15. Gallo RL. Human skin is the largest epithelial surface for interaction with microbes. J Invest Dermatol 2017;137:1213-4.

16. Um SW, Kim Y, Lee BB, Kim D, Lee KJ, Kim HK, et al. Genome-wide analysis of DNA methylation in bronchial washings. Clin Epigenetics 2018;10:65.

17. Belinsky SA, Palmisano WA, Gilliland FD, Crooks LA, Divine KK, Winters SA, et al. Aberrant promoter methylation in bronchial epithelium and sputum from current and former smokers. Cancer Res 2002;62:2370-7.

18. Breton CV, Byun HM, Wang X, Salam MT, Siegmund K, Gilliland FD. DNA methylation in the arginase-nitric oxide synthase pathway is associated with exhaled nitric oxide in children with asthma. Am J Respir Crit Care Med 2011;184:191-7.

19. Baccarelli A, Rusconi F, Bollati V, Catelan D, Accetta G, Hou L, et al. Nasal cell DNA methylation, inflammation, lung function and wheezing in children with asthma. Epigenomics 2012;4:91-100.

20. Yang Y, Haitchi HM, Cakebread J, Sammut D, Harvey A, Powell RM, et al. Epigenetic mechanisms silence a disintegrin and metalloprotease 33 expression in bronchial epithelial cells. J Allergy Clin Immunol 2008;121:1393-9.

21. Tripathi P, Awasthi S, Gao P. ADAM metallopeptidase domain 33 (ADAM33): a promising target for asthma. Mediators Inflamm 2014;2014:572025.

22. Stefanowicz D, Hackett TL, Garmaroudi FS, Gunther OP, Neumann S, Sutanto EN, et al. DNA methylation profiles of airway epithelial cells and PBMCs from healthy, atopic and asthmatic children. PLoS One 2012;7:e44213.

23. Kim YJ, Park SW, Kim TH, Park JS, Cheong HS, Shin HD, et al. Genome-wide methylation profiling of the bronchial mucosa of asthmatics: relationship to atopy. BMC Med Genet 2013;14:39. 
24. Breton CV, Byun HM, Wenten M, Pan F, Yang A, Gilliland FD. Prenatal tobacco smoke exposure affects global and gene-specific DNA methylation. Am J Respir Crit Care Med 2009;180:462-7.

25. Foster AM, Baliwag J, Chen CS, Guzman AM, Stoll SW, Gudjonsson JE, et al. IL-36 promotes myeloid cell infiltration, activation, and inflammatory activity in skin. J Immunol 2014;192:6053-61.

26. Collawn JF, Matalon S. CFTR and lung homeostasis. Am J Physiol Lung Cell Mol Physiol 2014;307:L917-23.

27. Santarlasci V, Cosmi L, Maggi L, Liotta F, Annunziato F. IL-1 and T helper immune responses. Front Immunol 2013;4:182.

28. White GP, Hollams EM, Yerkovich ST, Bosco A, Holt BJ, Bassami MR, et al. CpG methylation patterns in the IFNgamma promoter in naive T cells: variations during Th1 and Th2 differentiation and between atopics and non-atopics. Pediatr Allergy Immunol 2006;17:557-64.

29. Shang Y, Das S, Rabold R, Sham JS, Mitzner W, Tang WY. Epigenetic alterations by DNA methylation in house dust miteinduced airway hyperresponsiveness. Am J Respir Cell Mol Biol 2013;49:279-87.

30. Lluis A, Depner M, Gaugler B, Saas P, Casaca VI, Raedler D, et al. Increased regulatory $\mathrm{T}$-cell numbers are associated with farm milk exposure and lower atopic sensitization and asthma in childhood. J Allergy Clin Immunol 2014;133:551-9.

31. Perera F, Tang WY, Herbstman J, Tang D, Levin L, Miller R, et al. Relation of DNA methylation of 5'-CpG island of ACSL3 to transplacental exposure to airborne polycyclic aromatic hydrocarbons and childhood asthma. PLoS One 2009;4:e4488.

32. Breton CV, Siegmund KD, Joubert BR, Wang X, Qui W, Carey $\mathrm{V}$, et al. Prenatal tobacco smoke exposure is associated with childhood DNA CpG methylation. PLoS One 2014;9:e99716.

33. Yang IV, Pedersen BS, Liu A, O'Connor GT, Teach SJ, Kattan M, et al. DNA methylation and childhood asthma in the inner city. J Allergy Clin Immunol 2015;136:69-80.

34. Yang IV, Lozupone CA, Schwartz DA. The environment, epigenome, and asthma. J Allergy Clin Immunol 2017;140:14-23.

35. Rastogi D, Suzuki M, Greally JM. Differential epigenome-wide DNA methylation patterns in childhood obesity-associated asthma. Sci Rep 2013;3:2164.

36. Kwon NH, Kim JS, Lee JY, Oh MJ, Choi DC. DNA methylation and the expression of IL-4 and IFN-gamma promoter genes in patients with bronchial asthma. J Clin Immunol 2008;28:13946.

37. Baccarelli A, Wright RO, Bollati V, Tarantini L, Litonjua AA, Suh HH, et al. Rapid DNA methylation changes after exposure to traffic particles. Am J Respir Crit Care Med 2009;179:572-8.

38. Nadeau K, McDonald-Hyman C, Noth EM, Pratt B, Hammond SK, Balmes J, et al. Ambient air pollution impairs regulatory T-cell function in asthma. J Allergy Clin Immunol 2010;126:845-52.

39. Baines KJ, Simpson JL, Wood LG, Scott RJ, Fibbens NL, Powell $\mathrm{H}$, et al. Sputum gene expression signature of 6 biomarkers discriminates asthma inflammatory phenotypes. J Allergy Clin Immunol 2014;133:997-1007.

40. Morales E, Bustamante M, Vilahur N, Escaramis G, Montfort $\mathrm{M}$, de Cid R, et al. DNA hypomethylation at ALOX12 is associated with persistent wheezing in childhood. Am J Respir Crit Care Med 2012;185:937-43.

41. Grabenhenrich LB, Gough H, Reich A, Eckers N, Zepp F, Nitsche O, et al. Early-life determinants of asthma from birth to age 20 years: a German birth cohort study. J Allergy Clin Immunol 2014;133:979-88.

42. Lee KW, Pausova Z. Cigarette smoking and DNA methylation. Front Genet 2013;4:132.

43. Joubert BR, Felix JF, Yousefi P, Bakulski KM, Just AC, Breton C, et al. DNA methylation in newborns and maternal smoking in pregnancy: genome-wide consortium meta-analysis. Am J Hum Genet 2016;98:680-96.

44. Yoon D, Kim YJ, Cui WY, Van der Vaart A, Cho YS, Lee JY, et al. Large-scale genome-wide association study of Asian population reveals genetic factors in FRMD4A and other loci influencing smoking initiation and nicotine dependence. Hum Genet 2012;131:1009-21.

45. Devereux G, Turner SW, Craig LC, McNeill G, Martindale S, Harbour PJ, et al. Low maternal vitamin E intake during pregnancy is associated with asthma in 5-year-old children. Am J Respir Crit Care Med 2006;174:499-507.

46. Forno E, Wang T, Qi C, Yan Q, Xu CJ, Boutaoui N, et al. DNA methylation in nasal epithelium, atopy, and atopic asthma in children: a genome-wide study. Lancet Respir Med 2019;7:336-46.

47. Zhou D, Li Z, Yu D, Wan L, Zhu Y, Lai M, et al. Polymorphisms involving gain or loss of CpG sites are significantly enriched in trait-associated SNPs. Oncotarget 2015;6:39995-40004.

48. Astle WJ, Elding H, Jiang T, Allen D, Ruklisa D, Mann AL, et al. The allelic landscape of human blood cell trait variation and links to common complex disease. Cell 2016;167:1415-29.

49. Murphy TM, Wong CC, Arseneault L, Burrage J, Macdonald R, Hannon E, et al. Methylomic markers of persistent childhood asthma: a longitudinal study of asthma-discordant monozygotic twins. Clin Epigenetics 2015;7:130.

50. DeVries A, Wlasiuk G, Miller SJ, Bosco A, Stern DA, Lohman IC, et al. Epigenome-wide analysis links SMAD3 methylation at birth to asthma in children of asthmatic mothers. J Allergy Clin Immunol 2017;140:534-42.

51. Clifford RL, Jones MJ, MacIsaac JL, McEwen LM, Goodman SJ, Mostafavi S, et al. Inhalation of diesel exhaust and allergen alters human bronchial epithelium DNA methylation. J Allergy Clin Immunol 2017;139:112-21.

52. Lovinsky-Desir S, Jung KH, Jezioro JR, Torrone DZ, de PlanellSaguer M, Yan B, et al. Physical activity, black carbon exposure, and DNA methylation in the FOXP3 promoter. Clin Epigenetics 2017;9:65.

53. Jung KH, Lovinsky-Desir S, Yan B, Torrone D, Lawrence J, Jezioro JR, et al. Effect of personal exposure to black carbon 
on changes in allergic asthma gene methylation measured 5 days later in urban children: importance of allergic sensitization. Clin Epigenetics 2017;9:61.

54. Prunicki M, Stell L, Dinakarpandian D, de Planell-Saguer M, Lucas RW, Hammond SK, et al. Exposure to NO2, CO, and PM2.5 is linked to regional DNA methylation differences in asthma. Clin Epigenetics 2018;10:2.

55. Jung KH, Torrone D, Lovinsky-Desir S, Perzanowski M, Bautista J, Jezioro JR, et al. Short-term exposure to PM2.5 and vanadium and changes in asthma gene DNA methylation and lung function decrements among urban children. Respir Res 2017;18:63.

56. Yiannakopoulou E. Modulation of lymphangiogenesis: a new target for aspirin and other nonsteroidal anti-inflammatory agents? A systematic review. J Clin Pharmacol 2012;52:174954.

57. Pan MR, Chang HC, Chuang LY, Hung WC. The nonsteroidal anti-inflammatory drug NS398 reactivates SPARC expression via promoter demethylation to attenuate invasiveness of lung cancer cells. Exp Biol Med (Maywood) 2008;233:456-62.

58. Tahara T, Shibata T, Nakamura M, Yamashita H, Yoshioka D, Okubo M, et al. Chronic aspirin use suppresses CDH1 methylation in human gastric mucosa. Dig Dis Sci 2010;55:54-9.

59. Cheong HS, Park SM, Kim MO, Park JS, Lee JY, Byun JY, et al. Genome-wide methylation profile of nasal polyps: relation to aspirin hypersensitivity in asthmatics. Allergy 2011;66:637-44.

60. Momparler RL. Pharmacology of 5-Aza-2'-deoxycytidine (decitabine). Semin Hematol 2005;42(3 Suppl 2):S9-16. 